\title{
Modeling, Simulation and Control of Prosthetic Hand using SimMechanics
}

\author{
Beyda TAŞAR ${ }^{\# *}$, Arif GÜLTEN^ and Oguz YAKUT" \\ \#Department of Mechatronics, ^ Department of Electrical and Electronics Elazig, Firat University, Engineering, Turkey
}

Received 01 Jan 2018, Accepted 01 March 2018, Available online 03 March 2018, Vol.8, No.2 (March/April 2018)

\begin{abstract}
In recent years, researches about design and control of prosthetic, orthotics devices have been developed rapidly. Modeling and testing process of these devices requires long time. Matlab/SimMechanics Toolbox is a very effective and easy for modeling and analyzing of mechanical system. This paper presents the multi body simulation, analysis and control of 15 DoF prosthetic hand. Prosthetic hand 3D model is designed using SolidWorks, according to structural of the adult human hand. Hand pattern are demonstrated via MATLAB SimMechanics toolbox. PID controller response for each joints of fingers are presented.
\end{abstract}

Keywords: Prosthetic hand, analysis, simulation, control, SimMechanics

\section{Introduction}

People may lose limbs because of injuries, accidents, medical conditions, or congenital hereditary disorders. The prosthetic hand takes the place of the missing limb and imitates its function when the people lose your own hand because of these situations (C. L. Taylor et al, 1955).

The complexity and motion types number increase in direct proportion to the number of joints in a limb. For this reason, biological hand movement is quite complex (L. Ungureanu et al, 2005). Human hand has got countless patterns such as hand-off, hand-on, thumb-index finger touch, thumb-middle finger touch, point an object, gripping big object such as a bottle, grip a card with two fingers etc. The prosthetic imitating the movements of the human hand must also possess these abilities. Three main factors enable the functional and visual prosthetics to be used like a biological hand:

1) Human- Prosthetic hand cognitive interaction (A. O.I Mohammadreza et al, 2007; M.I. Ibrahimy el al, 2012; E Scheme et al, 2011; M. Khezri et al, 2011; W. M. B. W. Daud et al, 2013; X. Chen et al, 2013; P. Manimegalai et al, 2013).

2) Prosthetic hand mechanical design and modeling (H.Rakibul et al, 2013; R., Hasan et al, 2013) and

3) Perform the position and speed controls of each joint efficiently and precisely (W. Widhiada et al, 2011; K. Englehart et al, 2003; M. Asghari Oskoei et. al, 2007; J. Chu et al, 2005).

*Corresponding author's ORCID ID: 0000-0002-4689-8579, DOI: https://doi.org/10.14741/ijcet/v.8.2.2
In literature generally Surface Electromyography (sEMG) signals are used to recognize of human motion desire. EMG is used extensively to obtain valuable information about neuromuscular activities and to determine human motion intended. Cognitive interaction networks between human and prosthetic device is first step of control strategy.

Recording, pre-processing, feature extraction and classification steps of EMG signals part of the studies within our project are explained in detail (B Tașar et al, 2017). In this article; mechanical design, modelling and position control of prosthetic hand issues were presented. Research concerning the design, modeling, and control of prosthetic hands is increasing day by day. The dynamic and kinematic analyses of the hand are one of the basic steps for the design and control of a prosthetic. Hand modeling is a set of mathematical expressions that describe the kinematic and dynamic behavior of the hand.

In order to evaluate performances of a mechanical system is used kinematical and dynamic analysis which is one of classical methods. But kinematical and dynamic analysis is too hard because of establishing of the mathematical solution for hand which occur five fingers and each finger has three dof. Analysis based on simulation are easier than mathematical solution of kinematics and dynamics (V. Fedák et al, 2014; The MathWorks Comp. 2007). SimMechanics, which is a block diagram method for simulation and modeling mechanism by bodies and joints, solve this mathematical solution problem easily via Newtonian dynamics of torques and forces (V. Fedák et al, 2014). The kinematical analyses using SimMechanics are independent from kinematic equations of mechanic 
system. Graphical represent method can be used easily for mechanical systems by connected block diagrams.

To get a better grasp of objects, multi-fingered prosthetic handles have begun to be developed. Mechanical design and modeling are of utmost importance for deciding the shape and size of the prosthetic hand, which will make the best possible gripping movement. Simulation is important in terms of making pre-fabrication analyzes and optimizing the design (W.F.B.W. Tarmizi et al, 2010). Analysis of the kinematics and dynamics of the mechanical model is easily accomplished by block modeling without the need for mathematical modeling with the SimMechanic ToolBox. Kinematic analysis performs the position and orientation of the mechanism resulting from the motion. Dynamic Analysis describes the relationship between a particular forces or moment effect and the velocity of motion, acceleration of the mechanism $(\mathrm{H}$. Bruyninckx 2005). There are many studies in the literature to increase the gripping ability of multifinger robots. Mahdi et al. performed kinematic modeling and simulation of SCARA robot using Matlab / Simulink (M. S. Alshamasin 2009). Y. Yavin (2000), involved in the study of the kinematic and dynamic analysis results of three graduated manipulators using computer simulation environment.. Machomad Ariato et al. were focus on developing of low cost anthropomorphic prosthetic hand and they designed 14 Dof prosthetic hand via SimMechanics first generation (M. Ariyanto et al, 2016 (a); M. Ariyanto et al 2016 (b); M. Ariyanto et al 2016 (c)). Asif Mahmood Mughal (2017) was presented analytical modeling of hand via SimMechanics and PID controller response of five finger. Roshan Kumar Hota et al. (2016) developed a robotic prosthetic hand capable of producing ten grip patterns and simulated hand pattern via SimMechanics in their study.

In this study; fifteen degree of freedom prosthetic hand is modeled according to structural characteristics of an adult human hand using SolidWorks. Then motion analysis of hand simulated via SimMechanics. Positions of each prosthetic finger are controlled PID controller. Also PID controller is designed to content the performance criteria for track of the reference. PID controller performance is tested with five hand motion pattern, which are hand on, hand off, thumb-index touch, thumb, middle touch, thumb-ring touch and thumb-little touch motions.

\section{3D Modelling of the prosthetic hand using SolidWorks}

The human hand has high functionality and modeling is a very complex mechanism. The reason for this is the high degree of freedom. In other words, Human hand has a large number of joints that act independently of one another. As shown in Figure 1, each finger is made up of three small bones and connected joints. These small bones are called "Proximal phalanx", "Middle phalanx". "Distal phalanx" respectively. The distal interphalangeal (DIP) and proximal interphalangeal (PIP) joints have 1 DOF owing to rotational movement and metacarpophalangeal (MCP) joint has 2 DOF owing to adduction-abduction and rotational motions Kinematics and dynamics features of Index, middle, ring and little fingers are similar. But thumb is the most complex physical structure compared to others and thumb has 5 DOF (W.F.B.W. Tarmizi et al, 2009; J. K Salisbury et al, 1985; S.C. Jacobsen et al, 1986).
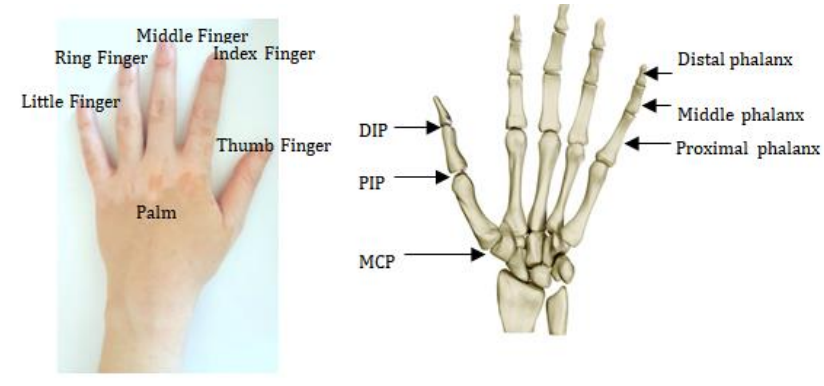

Figure 1 Structure of human hand

Physical model development of a multifunctional prosthetic hand starts by identifying its parameters: structural characteristics of the human hand like length and width of all fingers and hand palm, number of individual joints of each finger etc. Firstly an adult man hand characteristics are obtained as given in Table 1.

Table 1 Dimensions of parts of the hand

\begin{tabular}{c|c|c|c|c|c|c}
\hline \multirow{2}{*}{$\begin{array}{c}\text { Dimensions } \\
\text { of parts of } \\
\text { the hand }\end{array}$} & \multicolumn{2}{|c|}{$\begin{array}{c}\text { Dimensions of } \\
\text { First link }\end{array}$} & \multicolumn{2}{c|}{$\begin{array}{c}\text { Dimensions of } \\
\text { Second link }\end{array}$} & \multicolumn{2}{c}{$\begin{array}{c}\text { Dimensions of } \\
\text { Third link }\end{array}$} \\
\cline { 2 - 7 } & $\begin{array}{c}\text { Length } \\
\text { (mm) }\end{array}$ & $\begin{array}{c}\text { Width } \\
\text { (mm) }\end{array}$ & $\begin{array}{c}\text { Length } \\
\text { (mm) }\end{array}$ & $\begin{array}{c}\text { Width } \\
\text { (mm) }\end{array}$ & $\begin{array}{c}\text { Length } \\
\text { (mm) }\end{array}$ & $\begin{array}{c}\text { Width } \\
\text { (mm) }\end{array}$ \\
\hline Thumb & 70 & 30 & 45 & 30 & 40 & 30 \\
\hline Index Finger & 55 & 30 & 40 & 25 & 30 & 25 \\
\hline $\begin{array}{c}\text { Middle } \\
\text { Finger }\end{array}$ & 55 & 30 & 50 & 26 & 40 & 26 \\
\hline Ring Finger & 55 & 30 & 40 & 25 & 30 & 25 \\
\hline Pinky & 30 & 30 & 40 & 25 & 30 & 25 \\
\hline Palm & 130 & 120 & & & &
\end{tabular}

Then a suitable prosthetic hand 3D model is designed using SolidWorks program presented in Fig. 2 base on this information table.

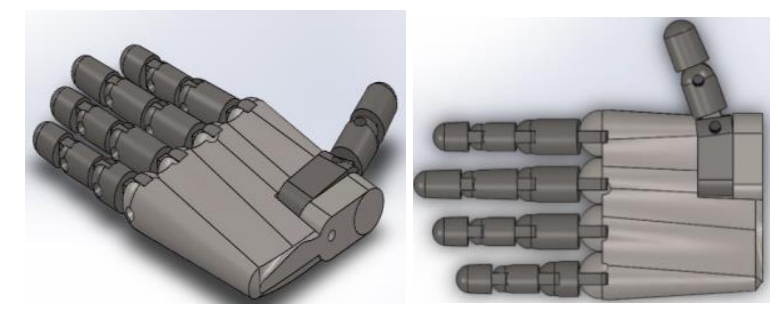

Figure 2 Visualization of the multifunctional prosthetic hand imported from the 3D model into the SolidWorks program 


\section{Simulation and analysis of prosthetic hand using SimMechanics}

SimMechanics ${ }^{\text {} м}$ is a simulation package that enables three-dimensional modeling of mechanical systems. This package, running in the Simulink environment, extends the Simulink environment with multi body mechanical modeling with its extensive function library. SimMechanics toolbox contains real system components, which bodies, joints, constraints, transform, forces and torques to design real mechanical system dynamics [31-36] (Y. Shaoqiang et al, 2008; I. Kakadiaris et al, 2000; C. Yang et al, 2010; W. Deng, et al, 2009; D. Gao et al,2006; L. T. Dung et $a l, 2010)$.
The 15-dof prosthetic hand was modeled in the first generation of SimMechanics. When the 3D physical hand model, which is developed in the SolidWorks program, is exported into the SimMechanics, each finger is automatically shaped individually and formed as a mechanic chain strip mounted on the palm area. Shape of the prosthetic hand parts are shown in Figure 3 with exported SimMechanics scheme because of better understanding.

Movement of one part relative to the other (rotation or translation) is determined in the joint module. A rotary joint was chosen for the connection of the finger bones. There are three revolute joints on each finger, namely a total of 15 joints (degrees of freedom). The model can be input using input, force, seed or moment module.

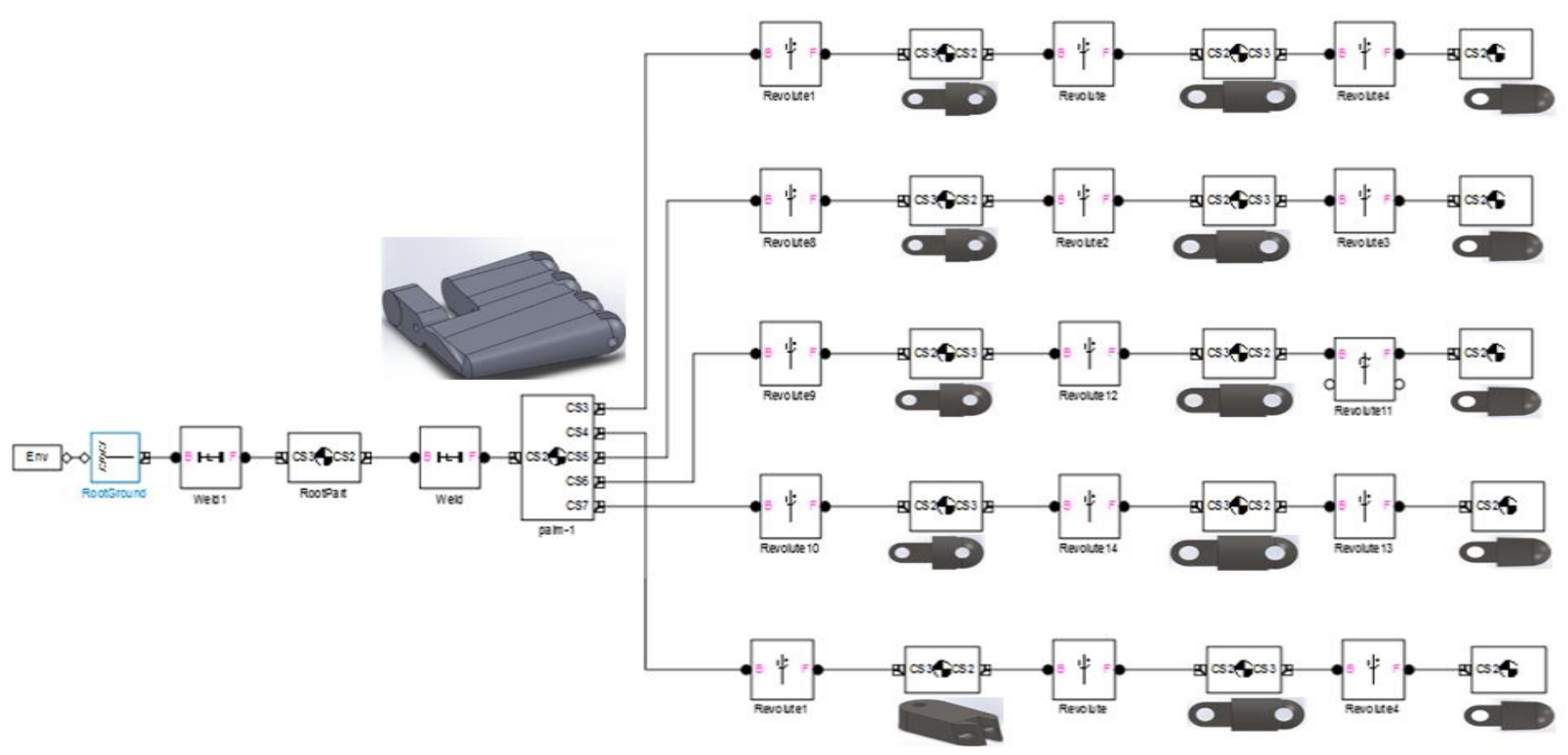

Figure 3 Program scheme of the 15-DOF multifunctional prosthetic hand in SimMechanics

Table 2 Reference angle value of finger for six hand pattern

\begin{tabular}{|c|c|c|c|c|c|c|c|c|c|c|c|c|c|c|c|c|}
\hline \multirow{2}{*}{\multicolumn{2}{|c|}{$\begin{array}{c}\text { Hand Pattern and } \\
\text { Joint Rotation Angle } \\
\text { Table }\end{array}$}} & \multicolumn{3}{|c|}{$\begin{array}{l}\text { Index } \\
\text { Finger }\end{array}$} & \multicolumn{3}{|c|}{$\begin{array}{l}\text { Middle } \\
\text { Finger }\end{array}$} & \multicolumn{3}{|c|}{$\begin{array}{l}\text { Ring } \\
\text { Finger }\end{array}$} & \multicolumn{3}{|c|}{ Little Finger } & \multicolumn{3}{|c|}{$\begin{array}{l}\text { Thumb } \\
\text { Finger }\end{array}$} \\
\hline & & $\theta_{1}$ & $\theta_{2}$ & $\theta_{3}$ & $\theta_{1}$ & $\theta_{2}$ & $\theta_{3}$ & $\theta_{1}$ & $\theta_{2}$ & $\theta_{3}$ & $\theta_{1}$ & $\theta_{2}$ & $\theta_{3}$ & $\theta_{1}$ & $\theta_{2}$ & $\theta_{3}$ \\
\hline 1 & Hand off & 90 & 90 & 90 & 90 & 90 & 90 & 90 & 90 & 90 & 90 & 90 & 90 & 90 & 35 & 35 \\
\hline 2 & humb-In & 90 & 30 & 25 & 0 & 0 & 0 & 0 & 0 & 0 & 0 & 0 & 0 & 60 & 10 & 0 \\
\hline 3 & Thu & 0 & 0 & 0 & 90 & 30 & 25 & 0 & 0 & 0 & 0 & 0 & 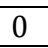 & 80 & 10 & 0 \\
\hline 4 & Thumb-Ring Touch & 0 & 0 & 0 & 0 & 0 & 0 & 90 & 35 & 0 & 0 & 0 & 0 & 100 & 20 & 0 \\
\hline 5 & Thumb-Little Touch & 0 & 0 & 0 & 0 & 0 & 0 & 0 & 0 & 0 & 90 & 35 & 0 & 115 & 20 & 0 \\
\hline
\end{tabular}

\subsection{Hand Pattern Input}

For the purpose the prosthetic hand to perform five selected hand pattern, the reference angle value for each finger joint is transmitted to joint actuators. As the hand reaches the desired pattern, the position, velocity and acceleration of each finger were measured. The reference of finger positions is show in Table 2 above.

\subsection{Model parameters}

The weight of the prosthetic hand is $200 \mathrm{gr}$, which is added to consider the effect of inertia. The hand characteristics of an adult individual in Table 3 are taken as reference in the selection of the dynamic model parameters.

Table 3 Parameters of Finger

\begin{tabular}{c|c|c|c}
\hline $\mathrm{L} 1$ & $0.057 \mathrm{~m}$ & $\mathrm{~J} 3$ & $0.00000155 \mathrm{kgm}^{2}$ \\
\hline $\mathrm{L} 2$ & $0.062 \mathrm{~m}$ & $\mathrm{k} 1$ & $0 \mathrm{Nm} / \mathrm{rad}$ \\
\hline $\mathrm{L} 3$ & $0.051 \mathrm{~m}$ & $\mathrm{k} 2$ & $0 \mathrm{Nm} / \mathrm{rad}$ \\
\hline $\mathrm{m} 1$ & $0.01852416 \mathrm{~kg}$ & $\mathrm{k} 3$ & $0 \mathrm{Nm} / \mathrm{rad}$ \\
\hline $\mathrm{m} 2$ & $0.01468982 \mathrm{~kg}$ & $\mathrm{c} 1$ & $0.005 \mathrm{Nms} / \mathrm{rad}$ \\
\hline $\mathrm{m} 3$ & $0.01492950 \mathrm{~kg}$ & $\mathrm{c} 2$ & $0.002 \mathrm{Nms} / \mathrm{rad}$ \\
\hline $\mathrm{J} 1$ & $0.00000189 \mathrm{kgm}^{2}$ & $\mathrm{c} 3$ & $0.005 \mathrm{Nms} / \mathrm{rad}$ \\
\hline $\mathrm{J} 2$ & $0.00000101 \mathrm{kgm}^{2}$ & $\mathrm{~g}$ & $9.18 \mathrm{~m} / \mathrm{s}^{2}$ \\
\hline
\end{tabular}




\subsection{Position Control of Hand}

There are many studies and method about position control of prosthetic device (P. J. Keyberd et al, 1995; H. Rakibul et al., 2013; R. Hasan et al, 2013; W. Widhiada, 2011; R. Gorez 1994). The positions of the joints in the finger are controlled by a Proportional, Integral and Derivative (PID) controller. The values of the controller's gains $K_{P}, K_{I}$ and $K_{D}$ are determined by the Zeigler Nicholson method to ensure that the system reaches steady state quickly without overshooting, as shown in Table 4. The PID control input-output relationship is written as Eq. (1) [42-46] (F. Vatansever et al, 2013; J. K. Astrom et al, 1995; S. Bennett et al,1993; E. Köse et al,2011)

$$
u(t)=K_{p} \cdot e(t)+K_{i} \cdot \int_{0}^{t} e(t) \cdot d t+K d \cdot \frac{d e(t)}{d t}
$$

Two suitable constant gain values for PID control of the prosthetic hand finger used in the simulation are given in Table 4.

Table 4 Gains used in simulation

\begin{tabular}{c|c|c|c}
\hline Constant Gain & $\mathbf{K}_{\mathbf{P}}$ & $\mathbf{K}_{\mathbf{I}}$ & $\mathbf{K}_{\mathbf{D}}$ \\
\hline Thumb -Index-Middle -Ring And Little & 5 & 0.05 & 0.005 \\
\hline
\end{tabular}

SimMechanics block diagram of one finger with three joints is shown in Figure 4. The PID motor diagram control is illustrated in Figure 5.

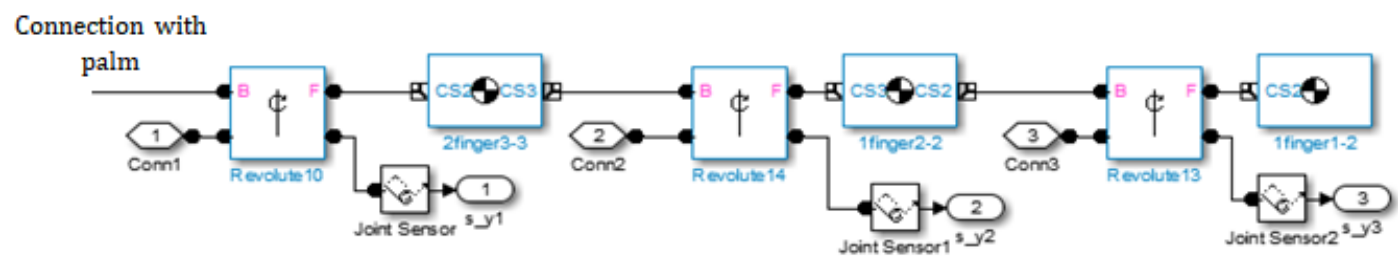

Figure 4 SimMechanics block of one finger with joint sensor and joint actuator

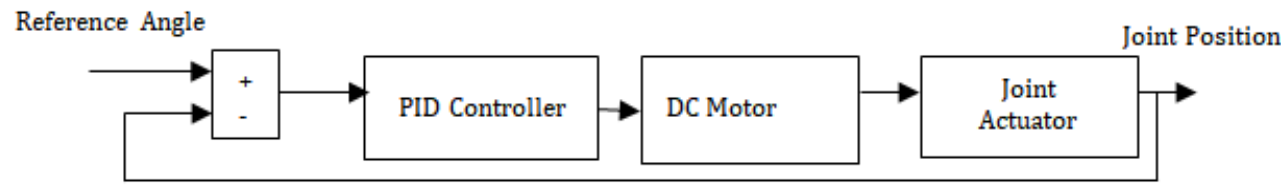

Figure 5 Designed PID controller for each joint of hand

\subsection{Results}

The joints of prosthetic hand SimMechanics model were transmitted and simulated in the following order respectively: 1) the reference signals for hand-off, 2) thumb-index finger touch, 3) thumb-to-middle finger touch, 4) thumb-to-ring finger touch, 5) thumb-to-little finger touch motions. In order to better observe the transient response obtained from the dynamic model, the change that occurred in the first $0.1 \mathrm{sec}$ is given. The five finger endpoint position changes and PID responses are shown in Figure 6 to 10 respectively for five fingers. And also Simulation images of prosthetic hand for five motions (hand-off, Thumb-Index touch, Thumb-Middle touch, Thumb-Ring touch, Thumb-Little touch) are presented.

When the hand is in the open position, the reference angle values for then hand-off movements are transmitted to the prosthetic hand model, and the angular movements that are performed by the endpoints of the five fingers are shown in Figure 6. All fingers except thumb reached steady state angle in 0.0812 sec. steady state time with 5.44 degree overshoots, and 0.01 degree steady state error values. And also thumb finger reached steady state angle in 0.0613 sec. steady state time with 1.807 degree overshoots, and 0.001 degree steady state error values.
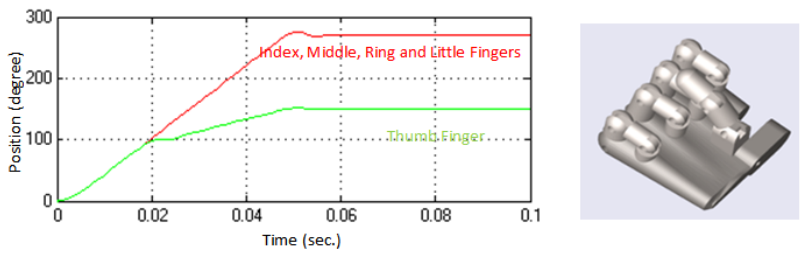

Figure 6 Hand-off motion (a) PID response of all fingers (b) Simulation Images of hand

When the hand is in the open position, the reference angle values for then thumb-index touch movements are transmitted to the prosthetic hand model, and the angular movements that are performed by the endpoints of the thumb and index fingers are shown in Figure 7.
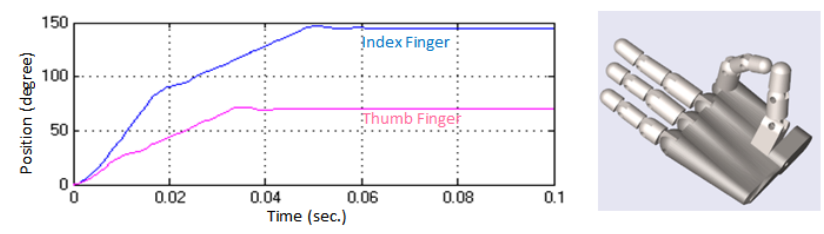

Figure 7 Thumb-Index finger touch motion (a) PID response of thumb and index fingers (b) Simulation Images of hand 
Index and thumb fingers reached steady state angle respectively in $\{0.0914,0.0698\}$ sec steady state time with $\{1.814,1.8424\}$ degree overshoots, and $\{0.0025$, 0.0038 degree steady state error values.

When the hand is in the open position, the reference angle values for then thumb-middle touch movements are transmitted to the prosthetic hand model, and the angular movements that are performed by the endpoints of the thumb and middle fingers are shown in Figure 8. Middle and thumb fingers reached steady state angle respectively in $\{0.0914,0.0908\} \mathrm{sec}$ steady state time with $\{1.814,1.816\}$ degree overshoots, and $\{0.001,0.001\}$ degree steady state error values.
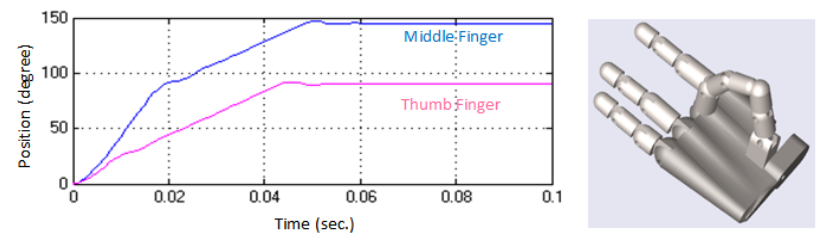

Figure 8 Thumb-Middle finger touch motion (a) PID response of thumb and middle fingers (b) Simulation Images of hand

When the hand is in the open position, the reference angle values for then thumb-ring touch movements are transmitted to the prosthetic hand model, and the angular movements that are performed by the endpoints of the thumb and ring fingers are shown in Figure 9. Ring and thumb fingers reached steady state angle respectively in $\{0.0682,0.0693\}$ sec steady state time with $\{1.795,1.815\}$ degree overshoots, and $\{0.002,0.0046\}$ degree steady state error values.
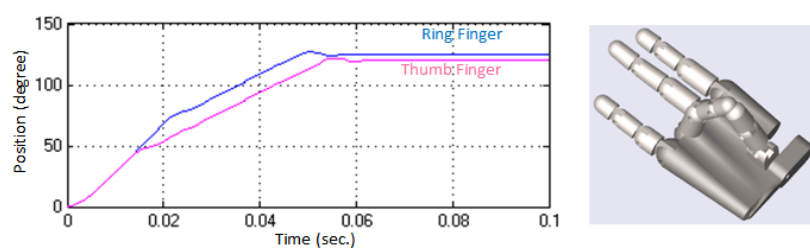

Figure 9 Thumb-Ring finger touch motion (a) PID response of thumb and ring fingers (b) Simulation Images of hand

When the hand is in the open position, the reference angle values for then thumb-little touch movements are transmitted to the prosthetic hand model, and the angular movements that are performed by the endpoints of the little and thumb fingers are shown in Figure 10.
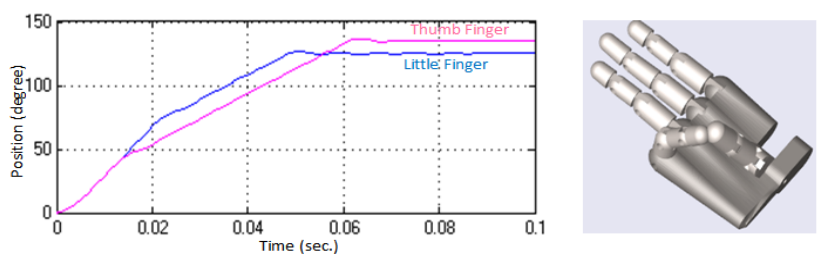

Figure 10 Thumb-Little finger touch motion (a) PID response of thumb and little fingers (b) Simulation Images of hand
Little and thumb fingers reached steady state angle respectively in $\{0.068,0.0813\}$ sec steady state time with $\{1.795,1.7982\}$ degree overshoots, and $\{0.001$, $0.008\}$ degree steady state error values.

\section{Conclusion}

The complexity of human limb movements, the number of independent movement, is increased proportion to the number of joints in the limb. If the wrist joints are ignored, human hand has got fifteen independent joints with three joint of each finger. For this reason, dynamic and kinematic analysis of hand is quite complex. Kinematics and dynamics analysis based on simulation is easier than mathematical solution. The kinematical analyses using SimMechanics are independent from differential equations of mechanic system. The simulation results have been demonstrated that finger motion control with PID control is achieved in a very fast, smooth and stable. Clearly, SimMechanics is effective way for analyzing of mechanical systems with its intuitive, easy, and high accuracy rate typical. It is benefit for analyzing mechatronic systems.

\section{Acknowledgements}

The subject of this article, which is Beyda TAȘAR's doctoral thesis, was supported by TÜBITAK under the Domestic Doctoral Scholarship Program for Priority Areas in 2211 C. In addition, the study was supported by Firat University Scientific Research Projects Management Unit within the scope of PhD Thesis Project number MF-14.25.

\section{Funding information}

There isn't used any funding source for this study.

\section{Conflict of interest}

There isn't any conflict between authors.

\section{Author contributions}

Oguz YAKUT and Beyda TAŞAR carried out the modeling and simulation of hand via Matlab and PID Controller design for pattern control. Arif GULTEN participated in its design and coordination and helped to draft the manuscript. All authors read and approved the final manuscript.

\section{References}

Alshamasin, M. S., (2009), Kinematic Modeling and Simulation of SCARA Robot by Using Solid Dynamics and Verification by MATLAB/Simulink, European Journal of Scientific Research, 37(3), 388-405.

Ariyanto, M., Munadi, M., Haryadi, G. D., Ismail, R., Pakpahan, J. A., Mustaqim, K. A.,(2016), Development of a Low Cost Anthropomorphic Robotic Hand Driven by Modified Glove Sensor and Integrated with 3D Animation, 
2016 IEEE EMBS Conference on Biomedical Engineering and Sciences (IECBES), 04 Dec - 08 Dec 2016, Hotel Pullman Kuala Lumpur Bangsar TBD Kuala Lumpur, Malaysia

Ariyanto, M., Munadi, M., Haryadi, G. D., Ismail, R., Pakpahan, J. A., Mustaqim, K. A., (2016), A Low Cost Anthropomorphic Prosthetic hand Using DC Micro Metal Gear motor, Proc. of 2016 3rd Int. Conf. on Information Tech., Computer, and Electrical Engineering (ICITACEE), Oct 19-21st, 2016, Semarang, Indonesia

Asghari Oskoei, M., and H. Hu, (2007), Myoelectric control systems - a survey, Biomedical Signal Processing and Control, 4 (4): 275-294.

Astrom K. J., and Hagglund, T., (1995), PID Controllers: Theory, Design and Tuning, Instrument Society of America, p. 343.

Bennett, S., (1993), A History of Control Engineering, Peter Peregrinus, p. 28-69.

Bruyninckx, H., (2005), The Robotic WEBook", www.roble.info/robotic/kindyn.

Chen, X., Wang, Z J., (2013), Pattern recognition of number gestures based on a wireless surface EMG system, Biomedical Signal Processing and Control, 8(2), 184-192.

Chu, J., Moon, I., Kim, S., Mun, M., (2005), Control of multifunction myoelectric hand using a real time EMG pattern recognition, in: Proceedings of the IEEE/RSJ International Conference on Intelligent Robots and Systems, China,p. 3957-3962.

Daud, W. M. B. W., Yahya, A. B., Horng, C.S, Sulaima, M.F., and Sudirman, R., (2013), Features Extraction of Electromyography Signals in Time Domain on Biceps Brachii Muscle, International Journal of Modeling and Optimization, Vol. 3, No. 6

Deng, W., Lee J.W., and Lee, KJ, (2009). Kinematics Simulation and Control of a New 2 DOF Parallel Mechanism Based on Matlab/SimMechanics, ISECS International Colloquium on Computing, Communication, Control, and Management, 08 Aug - 09 Aug 2009, Sanya, China

Dung, L. T.; Kang, H.J.; Ro, Y.S.; (2010). Robot manipulator modeling in Matlab SimMechanics with PD control and online Gravity compensation, IFOST Proceedings, 13 Oct 15 Oct 2010,University of Ulsan, Korea (South)

Eldin H.S.D, Manimegalai P.,(2013), Hand Gesture Recognition Based on EMG Signals Using ANN, International Journal of Computer Application, 3(2)

Englehart, K., \& B. Hudgins, (2003), A robust, real-time control scheme for multifunction myoelectric control, IEEE Transactions on Biomedical Engineering, 50(7): 848

Fedák, V., Ďurovský F., Üveges, R., (2014). Analysis of Robotic System Motion in SimMechanics and MATLAB GUI Environment, MATLAB Applications for the Practical Engineer, $\mathrm{Mr}$ Kelly Bennett (Ed.), InTech, DOI: 10.5772/58371. Available from: https:// www. intechopen.com/books/matlab-applications-for-thepractical- engineer/analysis-of-robotic-system-motion-insimmechanics-and-matlab-gui-environment

Gorez,R.; (1994). Fuzzy Control of Robotic Manipulators and Mechanical Systems, International Series on Microprocessor- Based and Intelligent System Engineering

Gao, D. X.; Xue, D. Y; (2006). Simulation Research of Robust Adaptive Control System for Robotic Manipulators Based on MATLAB/Simulink, Journal of System Simulation, 18(7): 2022-2025.

Hasan, R.; Rahideh, A.; Shaheed, H.; (2013). Modeling and Interactional Control of the Multi fingered Hand, Proceedings of the 19th International Conference on Automation \& Computing, Brunel University, and Uxbridge, UK. , 13 Sep - 14 Sep 2013, Brunel University, Middlesex, London, United Kingdom
Hota, R.K, Korrapati M. and Kumar, C.S, (2016), Kinematic Design of a Linkage Driven Robotic Hand for Prosthetics Capable of Achieving Ten Grips, 2016 International Conference on Robotics and Automation for Humanitarian Applications (RAHA), December 18 - 20, 2016Amrita University, Kerala, India,

Ibrahimy, M.I.; Khalifa, O.O.; Ahsan, M.R., (2012), EMG Motion Pattern Classification through Design and Optimization of Neural Network, In Proceedings of the International Conference on Biomedical Engineering (ICoBE), Kuala Lumpur, Malaysia, 27-28 February 2012; pp. 175-179.

Ismail R., Ariyanto, M., Caesarendra, W., Nurmiranto, A., (2016), Development of Robotic Hand Integrated with SimMechanics 3D Animation, 2016 International Seminar on Intelligent Technology and Its Application, $28 \mathrm{Jul}-30 \mathrm{Jul}$ 2016,The Santosa Villas \& Resort Lombok,Mataram, Indonesia

Jacobsen, S.C., Inversen, E.K., Knutti, D.F., Johnson R. T., and Biggers, K.B. (1986), Design of the Utah/MIT Dexterous Hand, Proceedings of the 1986 IEEE International Conference on Robotics and Automation, Washington DC: IEEE Computer Society Press, pp. 1520-1532.

Kakadiaris, I., Metaxas. D., (2000), Model-Based Estimation of 3D Human Motion, IEEE Transactions of Pattern Analysis and Machine Intelligence, 22(12), pp. 1453-1459.

Keyberd, P. J.; Holland, O. E.; Chappell, P. H.; Robert, S. S.; (1995), MARCUS: A Two Degree of Freedom Hand Prostheis with Hierarchical Grip Control, IEEE Transaction on rehabilitation Engineering, Vol. 3 No. 1.

Khezri, M.; Jahed, M. (2011), A neuro-fuzzy inference system for sEMG-based identification of hand motion commands IEEE Trans. Ind. Electron., 58, 1952-1960.

Köse, E., Abacl, K., Aksoy, S., (2011), Mekanik Sistemlerin PID ve Kayma Kipli Kontrol ile Modellenmesi ve Analizi, 6 th International Advanced Technologies Symposium (IATS'11), 16-18 May 2011, Elazı̆̆, Turkey

Mughal, A.M., (2017), Analytical Modeling Of Anthropomorphic Hand Using SimMechanics, Proceedings of 2017 14th International Bhurban Conference on Applied Sciences \& Technology (IBCAST), 10th - 14th January, 2017 Islamabad, Pakistan,

Mohammadreza A. O.I, Huosheng H., Review: Myoelectric control systems: A survey, Biomedical Signal Processing and Control, 2007, (2) pp. 275:294.

Rakibul, H., Vepar, S.H., and Hujijbert, H., (2013), Modeling and Control of the Barrett Hand for Grasping, 15th International Conference on Computer Modelling and Simulation, 10 - 12 Aprll 2013. Cambridge University, UK.

Shaoqiang, Y., Zhong, L., Xingshan, L, (2008), Modeling and Simulation of Robot Based on Matlab/SimMechanics, Proceedings of the 27th Chinese Control Conference, Kunming, Yunnan, China.

Salisbury, J. K., Mason, M.T., (1985), Robot Hands and the Mechanics of Manipulation, MIT Press, Cambridge, MA, 1985.

Scheme, E.; Englehart, K., (2011), Electromyogram pattern recognition for control of powered upper-limb prostheses: State of the art and challenges for clinical use, J. Rehabil. Res. Dev., 48, 643-659.

Taguchi H,. Araki, M., (2000), Two degree of freedom PID controllers. Proceedings of the IFAC Workshop on Digital Control: Past, Present and Future of PID Control, Elsevier, $\mathrm{p}$. 91-96.

Tarmizi, W. F. B. W., Adly, M. A., Amirfaiz, W., Elamvazuthi, I., and Begam, M., (2010), Modeling and Simulation of a MultiFingered Robot Hand, 2010 International Conference on Intelligent and Advanced Systems, 15-17 June 2010, Kuala Lumpur Convention Centre Kuala Lumpur, Malaysia. 
Tarmizi, W.F.B.W., Elamvazuthi, I., and Begam, M., (2009), Kinematic and Dynamic Modeling of a Multi-Fingered Robot Hand, International Journal of Basic \& Applied Sciences IJBAS-IJENS, Vol:09 No:10, 2009

Tașar B, Gülten A., (2017). EMG-Controlled Prosthetic Hand with Fuzzy Logic Classification Algorithm, Modern Fuzzy Control Systems and Its Applications, Dr. S Ramakrishnan (Ed.), InTech, DOI: 10.5772/intechopen.68242. Available from: https://www.intechopen.com/books/modern-fuzzycontrol-systems-and-its-applications/emg-controlledprosthetic-hand-with-fuzzy-logic-classification-algorithm

Taylor C. L. and Schwarz R. J., (1955), The anatomy and mechanics of the human hand, Artificial Limbs, vol. 2, pp. 22-35.

The MathWorks.Inc, (2007), SimMechanics User's Guide March.
Ungureanu, L., Drăgulescu, D., (2005), Modeling a Human Finger as an Automatic System, 11th International Conference on Vibration Engineering, Timisoara, Romania September 27 - 30, 2005

Vatansever, F., Şen, D., (201),. Genetik Algoritma Tabanlı PID Kontrolör Simülatörü Tasarımı, Uludağ Üniversitesi Mühendislik-Mimarlık Fakültesi Dergisi, 18(2)

Widhiada, W., Douglas, S.S., Jenkinson I.D., and Gomm, J.B., (2011). Design and Control of three fingers motion for dexterous assembly of compliant elements, International Journal of Engineering, Science and Technology, Vol. 3, No. 6, pp. 18-34

Yang, C.; Ye, Z.; Peter, 0.O.; Han, J.; (2010). Modeling and Simulation of Spatial6-DOF Parallel Robots Using Simulink and SimMechanics, 978-1-4244-5540-9/10/\$26.00 @IEEE

Yavin Y., (2000), Control of a Three-Link Manipulator with a Constraint on the Velocity of its End-Effector, Computers and Mathematics with Applications 40 (2000) 1263-1273 